\title{
Pensions design: Proposals for the 21st century
}

Received: 22nd December, 2005

\section{John Wilson}

is Head of Research at HSBC Actuaries and Consultants (HACL). He has over 20 years of pensions industry experience. He is also an Associate of the Chartered Insurance and Pensions Management Institutes, as well as a law graduate. He is currently studying towards a Masters in Business Law. He joined HACL in 1999 and heads the Research team responsible for ensuring that the company and its clients keep up to date with all developments in pension law and practice. He writes and speaks widely on pension matters and is the current Chairman of the Society of Pensions Consultants Legislation Committee.

\section{Stewart Lee}

joined HSBC Actuaries and Consultants in February 2005, and is based in their Edinburgh office. His role is concentrated on research into emerging pensions legislation and trends, but he also retains a scheme actuary certificate and an involvement in client work. He was previously a worldwide partner with Mercer Human Resource Consulting Limited, where he filled both client consulting and internal operational roles. He graduated from Glasgow University in 1975, with an Honours degree in mathematics and natural philosophy, and is a fellow of the Faculty of Actuaries, with over 25 years of pension consulting experience. He has been a speaker at many industry seminars and training events over that period.

\begin{abstract}
This paper considers, in the context of the current defined benefit to defined contribution trend, whether there is a 'third way' for pensions; ie an alternative to moving from one end of the pension scheme design spectrum to the other. It considers strategies for dealing with existing pension liabilities and options in terms of future pension provision.

As regards the former, various options are put forward with 'enhanced transfer values' elaborated upon and brought to life through a case study based on a real life situation. On the latter, alternatives to pure final salary and pure money purchase schemes are discussed. The benefits of the cash balance design are then amplified with another case study. The importance of pensions flexibility is emphasised.
\end{abstract}

Keywords: pension trends, managing liabilities, future scheme design, flexibility

John Wilson

HSBC Actuaries and

Consultants Limited

Spectrum House

2 Powderhall Road

Edinburgh EH7 4GB, UK

Tel: +44 0131456 6800;

Email:

john.w.wilson@hsbc.com

\section{INTRODUCTION}

Recent pension scheme surveys portray an ostensibly decisive picture of the UK pensions scene. In other words, although the survey numbers may be slightly different, the underlying messages are all broadly the same:

- most final salary pension schemes in the UK are considered to be underfunded;

- many have closed to new entrants and an increasing number to future accrual; - of those schemes that have not already closed, a large number are currently under review; and

- replacement schemes are nearly always money purchase.

There is, therefore, no doubt of the scale of the challenge that lies ahead. This paper, however, contends that the reported trends are not necessarily terminal and that there is actually a 'third 
way' for pensions. Indeed, research, as well as practical examples in the UK and abroad, highlight that:

- employee welfare is still a main driver behind offering workplace pensions;

- there is employer support for lowercost defined benefit schemes; and

- there may be a move away from the polarised pension scheme designs of both traditional final salary and conventional money purchase.

More specifically, a recent Association of Consulting Actuaries survey ${ }^{1}$ found that 69 per cent of employers favour a better balance of risk between individuals, employers, financial services firms and the State.

The present 'third way for pensions' has two limbs to it:

- one concerned with existing liabilities and the deficits already alluded to; and

- the other with future pension provision.

This paper will cover both limbs, illustrating the concepts through case studies.

Before turning to the substance of the paper, however, a quick mention of its timing; in other words, why now?

Well, essentially, in addition to the existing drivers behind change, namely the cost and complexity of providing traditional final salary pensions, there is currently an unprecedented and simultaneous reform of both the pensions tax and regulatory rules. Further, at the time of writing, the Turner Commission report is about to be published.

These reforms may present the best opportunity in years for employers to comprehensively reconsider the constitution of their scheme, its basis, and its detailed benefit structure.
Table 1 Options for corporate sponsors

Reduce accrual rate

Raise retirement ages

Cap pensionable salary growth

Allow members to convert more pension to cash

Offer members enhanced transfer values to leave

'Contingent funding arrangements'

Increase member contributions

Extend scheme waiting periods

Increase life assurance in lieu of survivor pension

Introduce flexible retirement

Contract back in to the State

Move the scheme offshore

\section{A THIRD WAY FOR PENSIONS: THE FIRST LIMB}

Experience suggests that some employers still remain committed to their final salary scheme, but, at the same time, they want to take steps to reduce and/or assert greater control over costs. This is where the first limb of the present third way for pensions comes in.

There are a number of options for such corporate sponsors, some of which are shown in Table 1. Space does not permit a commentary on all them, but some would benefit from a little elaboration.

- First, some of the options relate to the forthcoming single tax regime for pensions; for instance, to reduce post-retirement longevity risk, employers might allow members to convert more of their pension into cash using established commutation factors. This possibility has recently been picked up on by the media, leading to adverse commentary addressing only one side of the argument for exchanging pension for cash through factors that may not represent fair value.

- With regard to timing of retirement, just a couple of years increase in normal retirement age can make a significant difference to scheme liabilities. It now seems almost definite 
that the Pensions Commission's final recommendations will include measures related to working longer.

- On contracting-out and the value for money, or lack of it, provided by National Insurance rebates, the previously mentioned Association of Consulting Actuaries survey found that 72 per cent of employers want contracting-out to be abolished.

Moreover, some employers, such as Scottish \& Newcastle, have already contracted back into the State scheme in order to reduce liabilities and share risk with the State, notwithstanding the sometimes complex changes which have to be made to scheme benefits.

- Contingent funding arrangements are currently very topical. They come in a variety of forms and, even if they do not result in an immediate increase in pension scheme assets, they can at least give trustees more latitude in terms of scheme funding and deficit recovery periods. In recent times, ICI, National Grid Transco, Whitbread and M\&S have all used a contingent funding arrangement.

- Enhanced transfer values is an option recently implemented by the present authors, and this experience will shortly be related in a case study.

- Finally, moving offshore is a controversial one and the present authors are not aware of any scheme that has actually done it - yet. However, one application of recent draft regulations, which implement the EU pension funds Directive, relates to an employer in one member state that wishes to site its pension scheme in another member state for commercial reasons. Although it is early days, the Republic of Ireland is already promoting itself as the domicile of choice for emerging pan-European pension schemes.

\section{Case study 1: Enhanced transfer values}

Quite rightly, much time and attention is devoted to management of scheme assets. This case study is an example of liability management.

The case study is based on a real example. The detailed numbers have been altered to maintain client confidentiality, but the principles reflect real actions and outcomes.

To set the scene, there is a pension scheme under which active members represent a reducing proportion of total scheme membership - not so unusual in an environment in which the majority of schemes are closed to new entrants.

Deferred pensioner numbers are increasing.

The trustees and company have limited control over liabilities. In part, this reflects the fact that limiting salary increases has a reduced effect on total liabilities. In part, it reflects the fact that past legislation is inexorably removing discretion to grant pension increases at less than the rates that are funded. Contribution rates expressed as a percentage of payroll have become extremely volatile. In absolute terms, this may not be a big issue, but it is still perceived as unattractive by the company management.

Can the scheme's deferred pensioner liabilities be reduced? They can. Deferred pensions can be transferred out, but only if the members concerned give their consent.

Is there a business case for enhancing terms? There is, and it is illustrated by Figure 1.

The graph shows the value of $\mathcal{E}_{1} \mathrm{pa}$ of deferred pension at different ages, and on different valuation bases relevant to the scheme.

- The black bars represent the value on the transfer value basis.

- The pale grey bars represent the value 


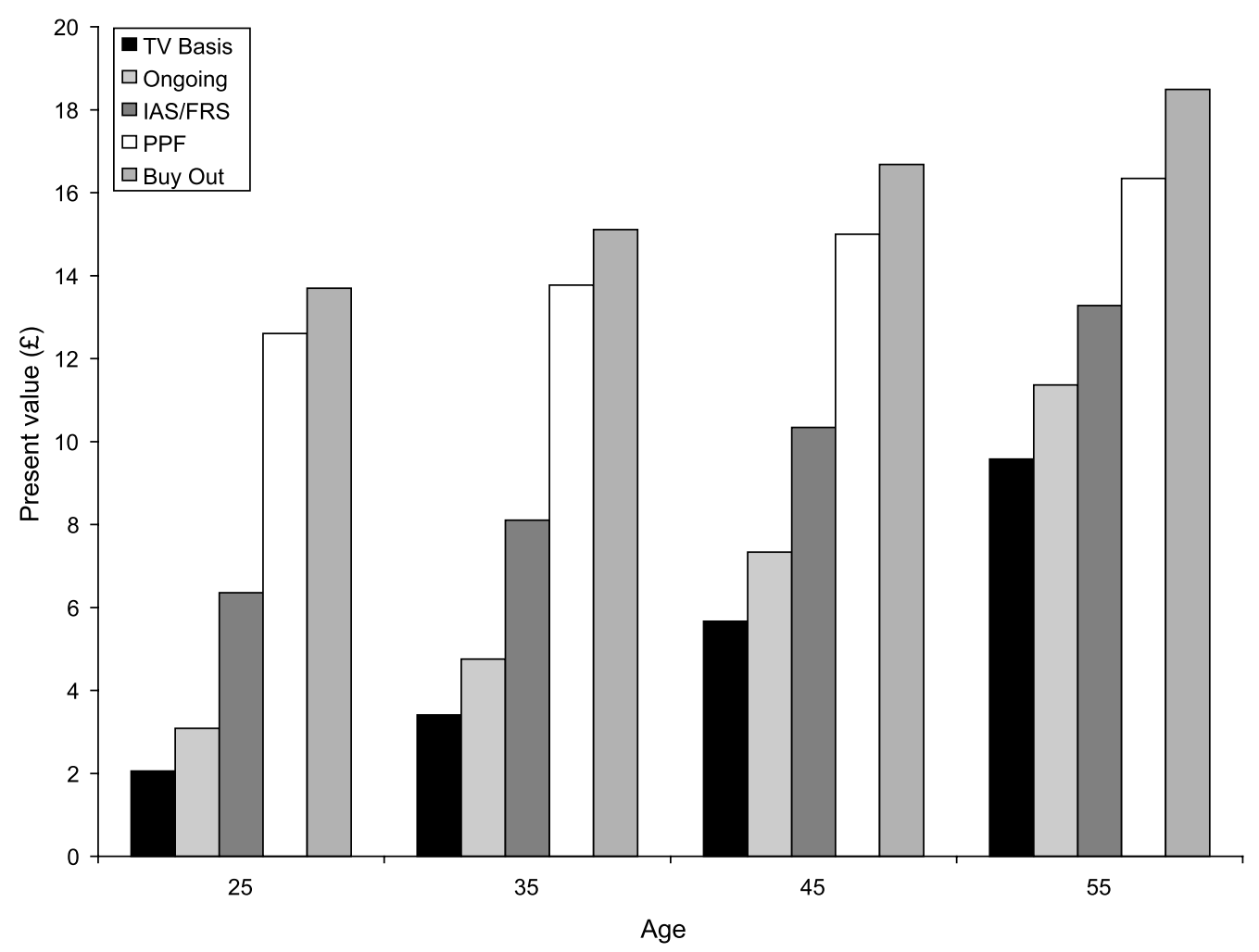

Figure 1: Illustration of value on various bases per 1 of deferred benefit

on the ongoing funding basis; ie the basis that drives the cash contributions paid to the scheme.

- The dark grey bars represent the value on the Financial Reporting Standard (FRS)17 basis, ie the basis that determines the amounts that appear as liabilities in the company's balance sheet.

- The white bars represent the value on the Pension Protection Fund (PPF) basis, ie the basis that determines the amount of PPF levy the scheme has to pay.

- The dark grey bars represent the value on a buy-out basis, ie the basis that would determine any debt on the employer in the event of scheme wind-up.

Looking first at the set of bars for a 55 -year-old, it can be seen that the transfer value for a deferred pensioner could be enhanced by over 10 per cent, and it would still be less than the value on the ongoing funding basis. So, if such a transfer value was paid, the ongoing funding position of the scheme would improve. The FRS17 position would improve more. The PPF position would improve even further, and the buy-out position would improve by the most of all.

Looking at the bars for a 25-year-old, it can be seen that a bigger enhancement of the transfer value could be granted, maybe up to 50 per cent, while still improving the funding position on the ongoing basis. The improvement in all the other funding positions is proportionately larger.

So what does all this mean can be done? In a nutshell, the idea is to offer members enhanced transfer values. It is 
stressed that this is an offer. There is no compulsion on the member. In fact, members also get a choice on the form of the enhancement. They can have a higher than normal transfer value with the company injecting the amount of the enhancement into the scheme or elect for the company to pay the cash enhancement direct to them.

What are the benefits to the various parties affected by this transaction?

- The deferred pensioners themselves get an improved transfer value offer.

- The company benefits from risk being passed to the member and hence has reduced defined benefit commitments going forward.

- The company also sees potentially improved ongoing, FRS, PPF, buy-out debt funding levels; ie a reduced requirement for cash contributions, lower balance sheet liabilities, lower PPF levies, and lower potential debts.

- The trustees will also be comfortable with potentially improved funding levels.

- Other scheme members (ie those not transferring) benefit from improved funding levels and increased company covenant

Before proceeding, however, a number of key issues should be addressed.

The modelling of potential enhancements and savings allows different scenarios to be investigated. Data for the relevant members are fed in, the value of their benefits on the different bases calculated, and different potential enhancements and different groups of members accepting or not accepting the enhanced terms is considered. One outcome of the modelling is a decision on the level of enhancements to be offered.

In addition, referring back to the earlier graph, the potential savings are proportionately greater in respect of younger members. Therefore, another outcome of the modelling is identifying that the offer should only be made to those below a certain age, or target population.

Separate legal advice for company/trustees is highly recommended. The two parties have different considerations, and both need to be assured that the process is legally acceptable. Tax, National Insurance and age discrimination implications are particular areas for advice.

Clear and careful communications to the members concerned is crucial. They have a choice to make. There is no intention to bias that choice in any way. The objective is to allow the members to make an informed decision, a point that a lot of commentary on the enhanced transfer option has missed.

Having carried out the modelling, and dealt with the other key issues described above, in the case study example, it is decided to make the enhanced transfer value offer to all deferred pensioners under the age of 52 . The response from the members is as follows:

- no reply: 12 per cent;

- member seeing independent financial adviser/still considering: 8 per cent;

- still trying to trace member: 10 per cent;

- declined offer: 23 per cent;

- accepted enhanced transfer value: 16 per cent;

- accepted direct cash payment: 31 per cent.

The striking point to note is that, in total, 47 per cent have accepted enhancement in one form or another; almost one half of those to whom the offer was made.

The financial effect is illustrated below. 
For simplicity, only the FRS17 position is illustrated, but corresponding effects would be seen in relation to the other bases relevant to the scheme.

- FRS17/IAS19 liability for members: £6.0m;

- Amounts paid to transferring members: - pension scheme transfer: $2.5 \mathrm{~m}$;

- company enhancement: $2.0 \mathrm{~m}$;

- total: $4.5 \mathrm{~m}$;

- Improvement in company balance sheet (FRS): $f_{1.5 \mathrm{~m}}$

- Improvement in scheme funding: 60-65 per cent.

\section{A THIRD WAY FOR PENSIONS: THE SECOND LIMB}

Looking forward now, to possible pension schemes of the future, it is best to start by explaining exactly what is meant, in this context, by a 'third way for pensions'.

This expression means that, if cost control and complexity are issues that cannot be addressed without changing the scheme benefit structure, then it is not always necessary to move from conventional final salary, one end of the pension scheme design spectrum, to pure defined contribution, the other end of that same spectrum.

Even if defined contribution (DC) appears to be the optimum way forward, it is, at very least, vital that proper due diligence is done first. This observation is equally relevant to:

- companies who have open final salary schemes, and are considering change;

- companies who have final salary schemes closed to new entrants, but want to consider changes for future accrual; and

- even companies who have switched to DC, but may be finding that it does not meet all their expectations.
Quite simply, for some employers, the pension scheme design 'middle ground', or 'risk-sharing arrangements', may be better than pure defined contribution.

By way of example, for employers that already have a final salary scheme, but are thinking of closing it, then it may be easier and more palatable if the replacement arrangement is a risk-sharing one. Furthermore, replacing final salary with a risk-sharing design may reduce or even eliminate the problems that can occur in having a 'two-tier' workforce when it comes to pension provision.

More generally, risk-sharing pension schemes can offer employers the control of costs that they seek with the additional benefits of:

- giving them the edge in the 'war for talent';

- helping them motivate and retain their employees; and

- operating as an effective workplace/succession planning tool.

All of these advantages are likely to grow in importance as the demographic changes of improved life-expectancy and falling birth rates take effect, and new age discrimination laws are implemented.

Thus, this paper advocates a proper pension partnership between employer and employee, where:

- the risks of pension provision are shared in an affordable and durable way;

- there is a better balance between cost and benefit certainty; and

- it is hoped, scheme design will not have to be revisited as frequently as it is now.

It is worth adding that, as a result of the transference of all the substantive risks of pension provision to employees, some 
Table 2 Potential apportionment of risk in the cash benefit design

\begin{tabular}{llll}
\hline Design risk & Final salary & Cash benefit & Money purchase \\
\hline Investment & Employer & Employer & Employee \\
Longevity & Employer & Employee & Employee \\
Earnings progression & Employer & Employer/employee & Employee \\
\hline
\end{tabular}

commentators have suggested that the final salary to money purchase trend may lead to employees coming back to the company in years to come, claiming that they did not appreciate the impact of the changes made and possibly seeking financial redress.

At this juncture it should be noted that this paper fully accepts that, for many employers, DC will still be the optimal scheme design. The contention is simply that, for some companies, DC is not the best option.

So, turning to the alternatives to conventional final salary or money purchase, these are, in theory, endless. Some of the main ones are listed below:

- shared-cost final salary;

- final salary/money purchase hybrid;

- 'CARE' (average salary);

- cash benefit/balance.

However, there are many variations on these themes, including the "no fixed retirement age' option described by Adair Turner, of the Pensions Commission, when he spoke about the concept of an average salary pension scheme with a retirement age which increases each five years by two-thirds of any increase in forecast life-expectancy at $65^{2}$.

This paper is going to focus on cash benefit (also known as cash balance and retirement balance). The reason for this is not just space constraints, but rather a conviction that cash benefit provides a solid foundation upon which it is possible to design a scheme possessing all the risk-sharing attributes that have already been mentioned. Furthermore, the risk-sharing structure is also logical. Broadly speaking, the employer carries the risk pre-retirement, and the employee deals with it post-retirement.

So, what is it? The cash benefit plan, which comes in a variety of forms, is already well established in the USA, and is also beginning to feature in other countries, such as the Netherlands, Japan and Australia.

For present purposes, cash benefit is simply a defined benefit scheme that defines the promised benefit in lump sum terms and, because of this, the design can score highly in terms of employee appreciation - thereby ensuring that the company derives maximum value from the scheme.

A cash benefit plan could be based on final salary or average salary or capped salary.

For instance, instead of a scheme that provides $1 / 80$ th of final pensionable salary (FPS) for each year of service, members could be promised 20 per cent of that salary each year. This would provide 800 per cent of FPS after 40 years, with part of the benefit available as a lump sum and the balance used to secure a pension from the scheme or to buy an annuity on the open market or as part of a drawdown arrangement.

The value of members' 'accounts' can never go down (assuming employer and scheme remain solvent), so employers keep the pre-retirement investment risk under cash benefit which, in any event, 
they are probably better placed to manage and diversify.

However, responsibility for longevity risk can be passed to the individual members because they have to secure the future pension instalments.

This apportionment of risk can also be described using the familiar 'pensions cake'.

In a cash benefit scheme, the employer provides a whole cake - the defined cash benefit - and the employee must use it to secure an income in retirement. In a final salary scheme, however, the employer is providing slices of a cake for an indeterminate future period.

By utilising the average salary variant of cash benefit, it is also possible to share the earnings progression risk - as well as retaining control of the revaluation of benefits.

Table 2 shows the potential apportionment of risk in the cash benefit design, relative to final salary where all three of the risks in question lie with the employer and to money purchase where the risks fall on employees.

For employers with existing final salary plans, conversion of past, as well as future, benefit entitlements to cash benefit may present a further opportunity to partly de-risk corporate pensions.

Cash benefit may be given a further boost in the UK following the tax simplification measures that come into effect in April. This is because existing revenue limits on pension benefits are being replaced by a lifetime allowance, which, like cash benefit, is expressed in simple monetary terms ( $f, 1.5 \mathrm{~m}$ in 2006/7). In addition, cash benefit is arguably the best defined benefit design for use in conjunction with flexible retirement, which will also be available from April. The second case study will elaborate on this.

Finally, the design can be easy to communicate and administer. In fact, recent research ${ }^{3}$ suggests that, in conceptual terms, the administration of cash benefit may be easier than both final salary and DC schemes.

A second case study will be used to put this into a more practical context. However, before that, for completeness, one final observation about cash benefit and other risk-sharing designs.

Under the Pension Acts, and there are now three of them, with a fourth on the way, risk-sharing arrangements are largely subject to the same rules as final salary schemes. With employers citing pensions legislation as one of their biggest concerns then, in the absence of greater regulatory flexibility and incentive to innovate, persuading them that there really is a third way for pensions is always going to be an uphill struggle notwithstanding the fact that regulation should not drive pension scheme design.

That is why the present authors are lobbying the PPF for a reduced levy for cash benefit schemes, because they present less of a risk, and why they have written to Ministers calling on, inter alia, legislation that actually rewards risk sharing.

\section{Case study 2: Cash benefit scheme}

The main purpose of this case study is to illustrate the risk-sharing characteristics of a cash benefit design. However, it also illustrates some other attractive features of the design.

To set the scene, an employer wishes to contribute approximately 10 per cent of salaries towards members' pension benefits. For simplicity, it is assumed that there would be no compulsory employee contributions to the arrangement. In practice, however, there probably would be.

Based on reasonable assumptions for membership profile, investment returns, 
inflation, salary growth, mortality etc, the 10 per cent of salary would support a final salary pension of 0.85 per cent salary for each year of service. On the same reasonable assumptions, the average pension emerging from a defined contribution plan with 10 per cent contributions would be at the same level as the final salary pension.

If the 10 per cent of salary is applied towards a cash benefit design, then on the same reasonable assumptions, the benefit supported could be expressed as a cash fund of 15 per cent of final salary for each year of service.

Clearly, the cash benefit design has the same value - but, as indicated in the main body of this paper, the perceived value of a cash fund of 15 per cent of final salary for each year of service is potentially much greater than that of a pension of 0.85 per cent of final salary for each year of service.

However, this is not the point of the case study. Rather, the purpose is to contrast the different risk characteristics of the cash benefit design compared with traditional final salary pension and defined contribution. The different risk characteristics are brought out by assuming that actual experience is different from the reasonable assumptions referred to above.

First, consider what happens if investment returns are 1 per cent pa lower than the reasonable assumption.

- Under the traditional final salary design, the employer contribution will have to be increased. It would have to be increased to about 13.5 per cent of salaries. The employees' pensions would be unchanged.

- Under a defined contribution arrangement, the employer contribution rate would be unchanged but, on average, employees' pensions would be reduced by about one-third.
- Under the cash benefit design, employer contributions would have to be increased, but only to about 12 per cent of salaries, and employees' pensions would be reduced by about one-eighth. The risk is being shared between employer and employees.

The normal interpretation of risk is on the downside. However, in this context, risk can be beneficial too. If investment returns are 1 per cent pa higher than the reasonable assumption, then under a traditional final salary pension scheme the employer would get all the benefit in the form of reduced contributions.

Under defined contribution, the employees would get all the benefit in the form of increased pensions.

Under cash benefit, the upside is shared in the form of partially reduced employer contributions and partially increased employee pensions.

In the main body of this paper, it is argued that the risk-sharing characteristics of cash benefit are logical. This can be illustrated in terms of the case study example.

If member longevity improves by 20 per cent, then under the traditional final salary pension design, the employer contribution rate would have to increase by 20 per cent and employee pensions would be unchanged.

Under the defined contribution design, employer contributions are unchanged, but on average, employee pensions are reduced by 20 per cent.

Under the cash benefit design, just as under defined contribution, employer contributions are unchanged, but on average, employee pensions are reduced by 20 per cent. In other words, under the cash benefit design, mortality risk is entirely on the employees. Arguably, it is logical that mortality risk should not be an employer responsibility.

However, pre-retirement investment 
risk under a cash benefit design is entirely with the employer. Again, this is logical. Broadly speaking the employer has the risk for the period during which it may benefit from the employee's activity.

At this point, it is worth referring to a major piece of global research carried out recently by HSBC. ${ }^{4}$ This is titled 'The Future of Retirement' and looks at attitudes to retirement in a number of major global economies. What has emerged so far is a picture of striking optimism, with the following headline results:

- there is a new vision of later life;

- a global rejection of mandatory retirement ages; and

- a 'second life' encompassing a mixture of work, leisure and education.

In order to meet these aspirations, it would seem that a key requirement is flexibility in retirement arrangements. Cash benefit designs fit with this flexibility, while also providing some certainty for members that is not present with the money purchase design.

In the case study example, an employee retiring from the traditional final salary or defined contribution design on a salary of, say $£ 25,000$, after 40 years' service, would have a pension of $£ 8,500$ per annum.

However, a level pension (in 'real' terms) may not now fit the desired pattern of expenditure in old age. That pattern will depend on many individual factors, such as continuing work, property ownership, travel aspirations, family circumstances, provision for long-term care, etc.

The corresponding cash benefit is a fund of $\mathcal{E} 150,000$. This fits far better with the potential for flexible drawdown, in a pattern that meets an individual's requirements.

Flexibility is the future.

\section{References}

1 Association of Consulting Actuaries (2005) UK Pension Trends Survey.

2 Turner, A. (2003) 'The macro-economics of pensions', lecture to the Actuarial Profession, 2 September.

3 Department for Work and Pensions (2005), see www.dwp.gov.uk/asd

4 HSBC (2005) 'The Future of Retirement'; available at:

http://www.hsbc.com/public/groupsite/retirement_ future/en/_overview_future_of_retirement.jhtml (accessed 5 July, 2006). 